\title{
High Symmetry of Fluoro- and Oxofluoroelpasolites as a Consequence of Dynamic Orientational Disorder ${ }^{\dagger}$
}

\author{
Natalia Laptash * and Anatoly Udovenko \\ Institute of Chemistry Far Eastern Branch of RAS, Vladivostok 690022, Russia; udovenko@ich.dvo.ru \\ * Correspondence: laptash@ich.dvo.ru \\ † Presented at Symmetry 2017-The First International Conference on Symmetry, Barcelona, Spain, \\ 16-18 October 2017.
}

Published: 3 January 2018

There is a large family of $\mathrm{A}_{2} \mathrm{BMX}_{6}$ compounds $(\mathrm{A}, \mathrm{B}=$ monovalent cations or ammonium; $\mathrm{M}=$ metal; $\mathrm{X}=\mathrm{O}, \mathrm{F}$ ) with an elpasolite structure derived from a perovskite superstructure with doubled cell parameter. Named after the mineral $\mathrm{K}_{2} \mathrm{NaAlF}_{6}$, elpasolite compounds are cubic face-centered with Fm3m space group $(Z=4)$. We found new crystallographic features of this structure associated with the disordering of both anionic and cationic positions, especially in the case of ammonium fluoro- and oxofluorometallates. The disorder in these compounds has a dynamic nature. Upon cooling, they undergo phase transitions of the order-disorder type with a rather large value of entropy change. It is virtually impossible to differentiate oxygen and fluorine atoms by $\mathrm{X}$-ray diffraction in disordered structures. We found that it became possible in the case of dynamically disordered oxide fluoride polyhedra. During such dynamics, the central atom is shifted towards the edge, face, or apex of the octahedron, giving its disordering on the cuboctahedron, cube, or octahedron, respectively. Such a displacement enables one to identify the $\mathrm{O}$ and $\mathrm{F}$ atoms owing to the inherent differences between $\mathrm{M}-\mathrm{O}$ and $\mathrm{M}-\mathrm{F}$ bondings and determine the real polyhedral geometry. 